\title{
Coming Home to School: Challenges and Strategies for Effective Teaching with Military Veterans
}

\author{
Michel A. Sportsman, PhD \\ Assistant Professor of Education \\ Park University \\ Lisa Thomas, PhD \\ Assistant Professor of Education \\ Park University
}

This article is an analysis of the unique needs of returning service members at the college or university level that impact the teaching decisions made by instructors.

The article also discusses the challenges that service members are individually addressing while acclimating themselves to their new environment of learning. With the reduction in forces occurring after the Iraq and Afghanistan wars, many higher level learning institutions are struggling to adequately meet the needs of returning veterans. In turn, veterans often find that the style of instruction and the general college-level universe are difficult to negotiate. The combination of these factors can often result in veteran students performing below expectation or leaving school without finishing. The article proposes a variety of ways to understand and address these challenges including the use of Scholarship of Teaching and Learning (SoTL) strategies and characteristics.

\section{The Unique Challenges of Returning Veteran Students}

Ever since the American Revolution, after a military conflict has come to a close, there follows a military stand down or a reduction in the number of troops needed in the US military. The budgetary demands of keeping a large armed force at the ready can become prohibitive, resulting in the need to send many veterans back to civilian life. There may also be a multitude of other reasons why soldiers return to their previous lives or unexpectedly find themselves in civilian life after a number of years of military service. Thanks to GI Bill benefits and the need to find a job in the civilian world, colleges and universities across the nation historically have found an influx of veteran students in classrooms after combat is over (Cozza, 2015).

The situation of veterans has been no different in recent times. It has been a decade since the September $11^{\text {th }}$ attacks on the World Trade Center, and more than two million American military personnel have been deployed to Iraq, Afghanistan or both since August 2001. More than half of those who have served in Iraq and Afghanistan have been deployed more than once. As in the past, Americans now find themselves, as a society, in the position of managing a reduction in forces as the US gradually withdraws from both battle theaters. As the military presence draws down and the defense budget begins to shrink, thousands of service men and women have begun to transition from military service to the workforce and/or to college (Cozza, 2015).

According to Schafer (2014), the Army is downsizing to 490,000 troops from its current level of 522,000 . Defense Secretary Hagel has proposed even steeper cuts in his most recent budget proposal, recommending a standing army of 440,000 troops, the smallest number since World War II. One might ask how this is important to higher education. However, the reduction in active duty forces presents the potential for an increase rate of unique students on American campuses. While it may seem that the wind-down would not be a difficult challenge, colleges are recognizing that returning veterans represent more than simply an increase in numbers for

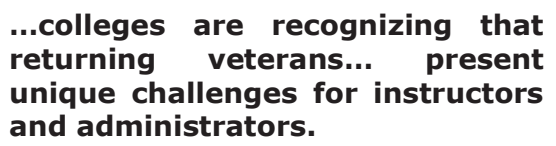


institutions of higher learning; they also present unique challenges for instructors and administrators. Therefore, institutions of higher learning are striving to serve the aspirations of these new students in effective ways so that they may return to civilian society to discover and begin productive careers. To accomplish this goal, institutions of higher learning recognize that they are dealing with a kind of student whose needs and demands for education or training are quite different from previous GI Bill students. This recognition requires adjustments in the classroom and on campus.

Nonetheless, the unique challenges of veterans transitioning from military service to a college environment are often not what faculty and staff at colleges are prepared for. Some of the stresses and adjustments of veteran students are readily observable and even typical for many new students; however, others may be more specific, subtle, and complex. If colleges seek to educate returning veterans, they must first learn about the special needs such students present and develop ways to accommodate them within classrooms and on campuses with appropriate support services, effective instructional strategies, and targeted academic and social advisement.

In an interview, Tom Tarantino of the Iraq and Afghanistan Veterans of America stated, "If colleges are not prepared to help transition soldiers from combat, you run the risk of losing an entire generation. The GI Bill isn't a 'thankyou for your service" ("Veterans Returning," n.d., para. 5). Tarantino echoes the beliefs of many military veterans, when he goes on to state:

[the GI Bill] is really a readjustment benefit. It is giving soldiers the opportunity to do something constructive for their minds and their bodies that gives them a mission and allows them to move forward in life. It's a backstop so you are not walking right off the plane from combat into the civilian world. It was designed to be a soft landing. ("Veterans Returning," n.d., para. 5)

Based on the thoughts of Tarantino (as cited in "Veterans Returning," n.d.), in order to help reintegrate returning veterans into their classes, it is important for professors to understand the transition of veteran students occurs in three levels simultaneously, adjustment to civilian life in general, adapting socially and academically to the universe of college level thinking and working, and the adjustment to classroom-based learning skills and interactions.

\section{Transitioning to Civilian Life}

The initial level of transition is challenging because the United States spends immense amounts of money and time preparing service members to be a part of a military force and training them for combat. Changing a raw recruit into a part of this highly specialized segment of society can be long and arduous and is always expensive (Cordesman \& Burke, 2012). The US Government spares little cost preparing young men and women to be part of the American fighting forces. Although the advertisements often refer to the Army as an Army of One, the truth is that new members of the Army, the biggest branch of the military, or any of the military services, must learn how to become a part of a group, to think like their peers, and to anticipate the needs of their mission. In a nation of individuals where independence from others is often a prized characteristic, this can be a very difficult transition, and once achieved, is a trait or behavior that the military constantly reinforces for automaticity. This is understandable considering the tasks and missions that military forces have and given the fact that failure to adhere to their training can result in death, often on a daily basis.

However, the reintegration of citizens back into their civilian lives, has typically received only a small fraction of the resources committed to their development into soldiers (Cordesman \& Burke, 2012). When military personnel 
finish their tours of duty and return to their homes, the transition they must navigate may include moving from a feeling of danger to safety, discomfort to comfort, camaraderie to solitude, chaos to order, and lawlessness to lawfulness. For veterans, returning back to the world they may have known before can be just as challenging and frightening as was the transition to being a soldier, only there is often little or no organized support for the return voyage home.

In this sense, service members often look forward eagerly to this time of transition, but it may have no clear individual pathway. As a result, they do not always find the journey is smooth, and coping with it becomes surprisingly difficult. Veterans soon realize that in addition to the total change of environment, there are many personal transitions, some large and some small, from military duty to civilian life. These challenges can make the hope of quickly returning to a civilian lifestyle somewhat unrealistic. They often discover that many things, from surroundings to relationships, have changed in their absence. Veterans may also discover that their priorities have now shifted. For example, they may realize that, as service members, they have developed a different set of values than they had prior to service which can conflict with the views of their families and friends. They may even have a new appearance (which may or may not be positive) or a new physical challenge. When they add the changes associated with taking on a college experience, to this multitude of adjustments, life as a new civilian can gradually or suddenly seem overwhelming, confusing, and/or frustrating for former military personnel. This process can leave veterans questioning where, if anywhere, they belong in this new world (Church, 2009).

\section{Transitioning to Campus Life}

A second level of re-integration into civilian life for soldiers is the return to college. At this level, soldiers often find that they have a variety of issues and obstacles to overcome in order to "fit in" with their new society. Five challenges for professors and instructors in higher education present themselves when they begin to work with returning veterans.

First, and perhaps most fundamentally, veterans must create or return to a different identity. No longer can they discover who they are, relative to others, by looking at badges, rank, or insignia. As Sherman (2010) noted, "The transitions are rarely seamless. For many, soldiering is not just a job or a career; it is an identity; it is who they become. Leaving it behind is not easy" (p. 4). In the place of the vocation they previously held, veterans suddenly find themselves as part of what may seem to be an undefined group where status or position is not determined by standardized advancement procedures or evaluations, and where dedication to compatriots rarely, if ever, approaches the level of "brotherhood" that permeates the military environment. As with any major life transition, the support of family, friends and the greater community is a critical component, but the transition to college life requires more because of the nature of the change itself.

This transition is an example of what the futurist, Joel Barker (2008), calls "a complete change of paradigm" (p. 2) a restructuring of their world view requiring veterans to entirely give up their previous assumptions. Understanding paradigms, as a strategy for organizing the world, can help in that effort, but prior knowledge can also limit how we perceive our current circumstances thereby narrowing our ability to change or to adapt. A paradigm shift is precisely what veterans often find so difficult, and yet they know that accepting and adapting to a new one is the first step to making a successful re-entry into the world of learning and work.

Johnson (1998) addresses this same issue by using a modern parable that echoes Barker's assertion that it is human habit and often easier to attempt to interpret a new situation from the relative safety of our old assumptions rather than to accept that the world has changed, and to adapt to new circumstances and form new paradigms. However, colleges sometimes miss this slow and sometimes painful change which must be made by all veterans who wish to return to campus. To assist institutions as they seek to facilitate this transition for returning GI's, there 
is support through agencies such as the Veterans Administration (VA), which advise colleges and universities that social support for this process from a variety of resources including formal military-dedicated entities such as Warrior Centers located on campuses across the US, the National Child Traumatic Stress Network, the National Center for PTSD, and the Field Operations Guide for Psychological First Aid (Bymer et al., 2006). All are adept in assisting new military students to make this multi-level transition. But, insofar as the transition is successfully made, the burden, in great proportion, rests on the shoulders of individual veterans who are often anxious or in a hurry to begin the process, yet nervous about the outcome.

Returning veterans often notes that the style of teaching and classroom management used by professors or instructors can make an important difference in this adjustment process as well. The deliberate use of broad-based teaching strategies arising from effective approaches to teaching and learning including many of the concepts included in the Scholarship of Teaching and Learning (SoTL) can provide a number of instructional options that can meet the needs of transitioning soldiers. In the words of Huber and Hutchings (2005), teachers often find "the work of the classroom [becomes] a site for inquiry, asking and answering questions about students' learning in ways that can improve one's own classroom and also advance the larger profession of teaching" (p. 1).

Once the initial social adjustment for veterans is in process, the academic and the social reintegration process can continue in tandem with their academics. Instructors and campus personnel can assist in this complex transition by keeping a few basic concepts and practices in mind which correlate well with several of the five characteristics proposed by Huber and Hutchings (2005).

A second challenge returning veterans often find is relating to or connecting with other traditional college students. For veterans, a principal goal of being part of a college student body is to facilitate their integration or return to civilian life, but due to their relative difference in age and because they have had significantly different experiences, veteran-students may often find traditional college students to be lacking in depth or simply callow. Given their previous experiences, veterans often can have little patience for what may be perceived to be "important" issues of campus life. In fact, returning military personnel have expressed that they felt "different" from the rest of the campus population. This perception of being different can actually increase the feeling of alienation that many veterans experience upon their separation from the military ("Veterans Returning," n.d.). If veterans feel un-connected in this way, it can make learning difficult or stress-related.

Thirdly, military personnel often find procedures on a college campus confusing or illogical ("Veterans Returning," n.d.). Although, this feeling can be experienced by any new student, it can be even more baffling for service members who have for the recent past experienced a

Returning veterans often note that the style of teaching and classroom management used by professors or instructors can make an important difference in this adjustment process...

period of doing things "the Army way" or "the Navy way" which is often highly regimented. Detailed steps are nearly always outlined for every military task, and strict compliance is expected. For these reasons, the "college way" of doing things may seem lax, unclear, or lacking in specificity. In this regard, advisors in colleges have an important role to play in the guidance of returning veterans. They should know that veterans will often, especially at the start of their college careers, require more detailed guidance than other advisees especially with respect to procedural matters. This need for detailed explanations should decrease as time passes and the service members become more acclimated to procedures and campus life in general. However, the assimilation process often does not proceed predictably and uniformly; assistance needs to be pro-active and at the ready. Academic and social advisors need to be intentionally attuned to (often subtle) clues that their veteran- 
advisees are experiencing frustration or confusion about college or classroom procedures.

A fourth issue that veteran-students may encounter concerns those service members who are returning from battle zones ("Veterans Returning," n.d.). While the military does provide counseling and transitioning services at the point of separation from the military, even the veterans themselves may not know they are experiencing combat-related stress. It is important to remember that these soldiers are leaving behind a period in their lives where perhaps everything is perceived as a "life or death" experience or decision. Campus life is generally not such an environment, of course, but disposing of the reactions and responses that combatexperienced veterans have developed over multiple battle-zone experiences takes time. Faculty and staff members should be aware that for months after they return home, some veteran-students retain a negative association with certain sounds, movements, or even smells. These can evoke discomfort or raise their level of concern within the learning environment, thus making learning difficult at best. A helpful solution is to work with the campus veteran support agency or Warrior Center to determine how instructors and staff can quickly recognize changes in affect or behavior that might indicate veteran-students are experiencing discomfort which can lead to poor classroom performance. Instructors can easily avoid or prevent what they may see as simple behaviors such as clicking pens, un-attended backpacks in the classroom, dropping books on the floor, or shouting, among others. Simple decisions such as these can help veterans develop a new sense of safety and ease on campus.

While very few members of a typical teaching faculty are properly trained or prepared to deal with significant diagnosed conditions such as PTSD, all faculty members should make themselves aware of the symptoms of post-traumatic stress and related conditions. Professional development activities should be offered to faculty to increase awareness of this serious and often under-reported condition. Recommended or required overviews of this condition may be arranged through the personnel office on campus. Self-guided classes much like those used to train faculty in other human resource issues may be effective, and professors may collaborate with other campus support agencies to develop assistance plans to benefit returning service members as they adapt to classrooms.

It should also be noted that many returning service members, although not diagnosed with PTSD, are nevertheless dealing with perhaps more common, or even mundane but very real stress that comes from resuming a previous role left behind prior to an unaccompanied assignment. Veterans often discover that they must immediately reassume their role of parent, spouse, and/or family caretaker upon returning from deployment, and even though they may be happily taking on these roles, the normal stress associated with them is magnified through the lens of combat zone experiences. Similarly, they may not have performed these duties for months, but returning service members must now pick up where they were before their departure, but they can find that, as Bob Dylan once said, "things have changed" in a variety of ways during the absence. It is possible new intrarelationship challenges have developed during the deployment. There is also the possibility that in spite of the support family members have maintained for their veterans during their absence, there may exist some latent resentment that can surface later. Also, family members, having fulfilled the role(s) of absent veterans while they were in combat, may now be reluctant to relinquish those responsibilities even though the service member is willing and desirous of resuming those tasks and roles. All of these scenarios may increase the already high level of stress that a service member is experiencing.

Finally, service members who are transitioning with new disabilities are a special category. In addition to their new specific and unique physical challenges, these service members may well be experiencing all of the previously mentioned challenges. Instructors, advisors, and professors will require significant training and preparation to successfully teach or advise veterans such as these. While the specific details of this training is beyond the scope of this discussion, it is important 
for instructors and professors to seek proper assistance from agencies such as those mentioned earlier and to plan well in advance if possible for working with soldiers such as these.

The following are some examples of the challenge of "fitting in" on campus and in the classroom as described by Huber and Hutchings (2005) and some examples of ways to facilitate the transition whether faculty members have veteran students in their classrooms, simply meet them crossing campus.

- Know that veterans are not all alike and their transitions, while having commonalities, may vary in pace and difficulty. Patience on the part of instructors will be important in facilitating the integration to campus life or the classroom. It should be noted, that professors' desire to exhibit the patience needed with returning soldiers, can be constrained by the requirements of on-line coursework or other exigencies that impact and limit the degree of flexibility they may control. Instructors, who have a returning veteran in their classes, can (and should) consult with Warrior Center staff members to determine if a specific course, whether on-line or face to face, is appropriate at the stage of any individual veteran's reintegration process. In this way, instructors and veterans support staff may collaboratively develop strategies for working with individual students. Point 5: "The work of teaching occurs in an almost infinite set of contexts - defined by discipline, student demographics, institutional types, pedagogical approach, curricular goals..." (Huber \& Hutchings, 2005, p. 35).

- Take time to get to know the returning military student. Find out how he/she learns best. Like all students each veteran will have a preference in this area. Two easily used strategies for this is to do an informal work analysis and/or to use a Gardner questionnaire. The informal analysis will furnish the instructor with a real-time example of a veteran's written work. These data can be an excellent preassessment barometer of the student's comfort level in the class, knowledge of prior or fundamental concepts, and degree of confidence in written expression. A more formal assessment such as the Walter McKinzie Multiple Intelligences (M.I.) Inventory based on the pioneering work by Dr. Howard Gardner, can give an instructor an even more detailed profile of the veteran's learning preferences. To avoid drawing unneeded attention to a veteran student in one's class, it may be advisable to administer the inventory to all students in the class. This can be valuable data to have about any students. A third approach is to begin to develop a comfortable informal dialogue with veteran students that are both non-judgmental and yet compassionate. Finally, based on all the data collected, professors should volunteer assistance to the veteran student if possible.

- Remember that instructors can provide many kinds of social assistance including emotional support, reassurance of self-worth, advice and information, and physical or material assistance. Point 1: "It means viewing the work of the classroom as asking questions about student learning" (Huber \& Hutchings, 2005, p. 1). This reassurance may take the form of informal updates about student performance, recommendations of study strategies or skills, referrals for additional assistance provided by the institution, and/or specific positive comments.

- Do not lower standards, yet do provide individualization. In personal experiences and based on multiple conversations with returning veterans, the authors find that veterans generally do not want to think they are receiving a lesser education, and yet many admit they may need additional time or other accommodations to complete work 
especially if they are beginning the transition to civilian life (Ackerman, DiRamio, \& Mitchell, 2009).

- Provide information, not prescriptions. Often the veteran-student knows very well what he/she needs to do to adapt or change. So, it is more helpful when instructors respond to questions as needed and ask specific questions about how things "are going". It is better to avoid general or vague questions such as "Are you doing OK?" because the answers seem usually be positive even if things are in fact not going well. And, the veteran may interpret the question as either meaningless pleasantry or possibly uncaring which does nothing to assist them in their efforts to re-integrate into civilian society (Ackerman et al., 2009). A professor may do far more good by giving one or two specific positive comments about a veteran's recent work or participation in class or his/her functioning on campus.

- As Rose (2010) suggests, the transition process is complex and has many facets, but the key idea is to treat a complex educational issue in a comprehensive and integrated way. Research by Ingala, SoftasNall, and Peters (2013) indicates that college adjustment, never an easy transition for students, is especially complex for non-traditional students such as veterans. They also report that measuring and quantifying progress on this challenge can be very difficult. Assessment of this transition becomes even more problematic when one adds in the variety of possible intervening variables including family responsibilities, mental health, and financial burdens that often accompany re-entry into civilian life.

\section{Transitioning to the Classroom}

As returning veterans begin to make the transition to civilian and campus life, the issue becomes a question of how do instructors in the classroom provide them with the best opportunity for academic success. The authors believe the answer lies in a multi-pronged approach that includes concepts based in the Scholarship of Teaching and Learning (SoTL). This model along with other supports can provide good answers to the teaching challenge that confronts college level instructors working with veteran students.

First, using the SoTL model can be central to the overall success of veteran students. There are five specific principles of the SoTL model that are especially noteworthy for instructors in general and may readily apply to the instruction of veteran students in higher education. These principles include: 1 . Inquiry into student learning; 2 . Teaching grounded in context; 3 . Sound methodology; 4 . Work conducted in partnership with students; and 5 . Work that is appropriately public (Huber \& Hutchings, 2013). Huber and Hutchings (2013), as well as others, have addressed the SoTL model in great detail, so it is not the purpose of this article to reiterate what others have described. Therefore it is useful and beneficial to begin with an understanding of this intriguing area of research. In addition, instructors' work with returning veterans can benefit from several other helpful research-based strategies working in concert with SoTL, to assist them in the effective instruction of veteran students. Regarding SoTL, work by Pat Hutchings, Mary Taylor Huber, and Anthony Ciccone, especially their book, Scholarship of Teaching and Learning Reconsidered (2011) is a good place to start to understand the relationship between the scholarly work of the professoriate and effective strategic teaching in higher learning.

Secondly, in informal conversations with returning soldiers, veteran students often express impatience with instruction that they find difficult to follow or that, to them, seems unclear in its direction. Conversations with veteran students on campus reveal that, among the many concerns expressed individually, they seem to prefer certain specific kinds of instruction over others. For example, they 
often seek opportunities to collaborate with others. An initial pilot survey of returning veterans has yielded support for this observation as well.

While Huber and Hutchings' (2013) first principle which proposes a careful inquiry into how all students prefer to learn, the results of the pilot survey would indicate that it is also worthwhile to pay special attention to the learning preferences of veterans in a class. An example of a brief survey that can facilitate gathering this data is included as an attachment and may be used as is or modified to fit the needs of individual instructors. The survey was designed with the four primary learning styles in mind (auditory, visual, kinesthetic, and intuitive or universal) and is based on the early work done in this area by Carbo (1986) and Fleming (2001). Carbo's (1986) initial work on reading styles along with the research done by Fleming (2001) is easily accessible and understandable by any instructor and aligns easily with principles of SoTL. Their work is easily used in the classroom as a diagnostic tool by instructors who may not have a background in elementary or secondary education. The broad categories used by Fleming serve as effective initial organizers for selecting strategies for learners. He also provides strategies and activities that engage students in each modality or learning style. The self-select questions on the survey allow students to identify a preference for one of the four styles of retaining information as the questions become increasingly more specific. Thus, the instructor can easily assess the results using a quick quantification or by looking at the questions in a more qualitative manner.

Third, Warrior Centers are service offices that provide support for veterans on local campuses, but which may not be available at all institutions. Also, Veterans Administration offices that are typically found on most campuses can also provide assistance for a variety of veteran-related needs including learning preference assistance. The efforts of these agencies have found success in supporting veterans' goals to remain in school and to complete their programs. Kathy Snead, director of Service Members Opportunity Colleges, a government-funded organization that helps veterans complete their degrees believes that a campus veteran's organization or office helps service members feel more engaged in student life. She agrees with Lawrence Braue who was recently referenced in an article by Suzanne Shafer, "indicating that institutions should, "...set up a one-stop shop, a center populated with people who [understand] the complex medical and financial benefit systems that they must navigate ... a full service veterans center." (Schafer, 2014, para. 22). A successful veterans' center should include academic advising, resources for counseling, financial aid, tutoring, mentoring, and other academic and social needs. If possible, a veterans' center can create a space for returning soldiers to meet, socialize and study. Colleges and universities should offer a customized "Veterans Orientation" for incoming student veterans at the beginning of each semester and establish learning communities with a service component geared toward helping families of veterans (Schafer, 2014).

Fourth, in collaboration with the VA or a veterans' center, a college should develop a campus-wide training response to PTSD. Although not confined to military personnel, this condition has come to our national collective attention since 2001 (Church, 2009). It can be beneficial to all college professionals who work with veterans to have access to trained faculty and staff who recognize the symptoms of PTSD and can refer such students to a designated liaison on campus. Several counseling representatives should be trained to deal with complex or deeper issues and offer ways for professors and advisors about how and where to refer such cases. To further build awareness, centers should provide for regular and continuing PTSD professional development training (McDonough, 2011).

In this connection, Operation Educate the Educator, a comprehensive federal program begun through the Joining Forces initiative started by First Lady Michelle Obama and Dr. Jill Biden has opened up opportunities for educators. This effort aims to educate, challenge, and spark action from all sectors of society to ensure veterans and military families have the recognition and support they have earned. More than one hundred US colleges and universities have signed on to the 
Joining Forces commitment that helps prepare educators to lead classrooms and develop school cultures that are responsive to the social, emotional and academic needs of military families.

A fifth classroom strategy recommended for instructors, who are working with returning service members, is to harness the power of collaborative activities. Military culture constantly reinforces the importance of "working as a team" in nearly all endeavors. Veterans who have been trained in this culture will not easily relinquish it and may find an emphasis on individual effort and work products to be confusing or difficult. In fact instructors may even find individual work submitted by veterans to be unfinished or otherwise inadequate (McDonough, 2011). McDonough (2011) believes that even if a soldier has TBI (Traumatic Brain Injury) incomplete or poorly done work does not give us a true or complete picture of the veteran student's skill level or knowledge which can lead us to make an inaccurate judgment of accomplishment or mastery of concepts. Collaborative activities such as Cooperative Learning activities can be effective for any students since it addresses higher level thinking at the comprehension, application, and/or analysis levels. Research by Bloom, Engelhart, Furst, Hill, and Krathwohl (1956) shows that learning requiring higher level thought processes has a greater chance of being long lasting. Therefore, instruction that requires veteran students to actively engage in the learning process and that encourages students to

A fifth classroom strategy recommended for instructors, who are working with returning service members, is to harness the power of collaborative activities.

work together to achieve a common goal may have the best chances for returning service members to achieve academic success. In many cases, service members may already feel isolated due to their own specific and unique experiences. But, after having been in a group-focused environment, veterans often welcome a group-based hands-on learning experience in their college classroom. Collaboration may have a better chance of engaging veteran-students while providing instructors with more accurate data on which to base evaluations and future lessons. It can also provide veteran students with a better insight into the learning preferences of their classmates and a new appreciation for their academic contributions.

Supporting this concept, Gagne (1962) who served as a consultant to the Pentagon from 1958 to 1961 determined that a specific model of instruction that includes a three-step instructional plan that is both simple and effective works best in military settings. This three-part design is still in use in military training programs today and includes: 1 . providing instruction on the set of component tasks that build toward a final more complex task; 2 . ensuring that each component task is mastered; and 3. sequencing the component tasks to ensure transfer to the final task. Gagne recommends that there be a clear, dependable, and predictable design used to develop all lessons so that students can focus on the content of the lesson without trying to discern the order or logic of the lesson which again connects to Huber and Hutchings (2013) principles. Careful, consistent, design for each lesson can assist veterans to make the transition to college level learning. Many researchers in education from Dr. Madeline Hunter at UCLA in the 1940s to Marzano (2003) in current times have said that planning of this type will ultimately benefit all students' learning, but providing the connection to previous military models can be of special help for professors wishing to effectively reach and instruct returning veterans in their classrooms.

Finally, a last strategy for assisting veteran service members is the coaching/advising approach advocated by Hallowell and Ratey (1994). Even though their original intent was to address the needs of students who have difficulty generally focusing on school work and other tasks, Hallowell and Ratey (1994), both medical doctors, advocate working with veterans individually. In a tutorial relationship professors and advisors should endeavor to isolate where learning stumbling blocks exist, work through those by breaking them down into smaller tasks, and coaching the student in the same ways as sports coaches. Their book provides a number of effective practical strategies for university level instructors to 
use in a tutorial relationship with individual students, especially those who may not be inclined to participate verbally in class.

In summary, the unique nature and needs of returning veterans and active duty military personnel present a new challenge for colleges and universities. As the American Council on Education-ACE report (2010) notes, recognizing the need to include more flexibility in our teaching and assessment of student needs not only benefits student veterans, but also other students who may profit from having the same flexibility extended to them. However, understanding, compassion, and planning for veterans' transitions must be thoughtful and intentional, as these students, while perhaps not traditional, present a rich opportunity to engage the college classroom. The use of research-based instructional strategies targeted for optimal learning for veteran students can make the experience better for students and instructors alike. Perhaps, of greater importance is the opportunity to support the student veterans in achieving their goals of remaining in school and earning their degrees.

\section{References}

Ackerman, D., DiRamio, D., \& Mitchell, R. (2009). Transitions: Combat veterans as college students. New Directions for Student Services, 2009(126), 5-14. Retrieved from http://onlinelibrary.wiley.com/journal/1 0.1002/(ISSN)1536-0695

American Council on Education-ACE. (2010). Accommodating student veterans with traumatic brain injury and post-traumatic stress disorder: Tips for campus and faculty. Retrieved from http://www.acenet.edu/newsroom/Documents/AccommodatingStudent-Veterans-with-TraumaticBrain-Injury-and-Post-TraumaticStress-Disorder.pdf

Barker, J. (2008). Putting our differences to work: The fastest way to innovation, leadership, and high performance. San Francisco, CA: Berrett-Koehler.

Barker, J. (1996). The Mondragon model: A new pathway for the twentyfirst century. In F. Hesselbein, M. Goldsmith, \& R. Beckhard (Eds.), The organization of the future (pp.109118). San Francisco, CA: Jossey-Bass.

Bloom, B. S. (Ed.), Engelhart, M. D., Furst, E. J., Hill, W. H., \& Krathwohl, D. R. (1956). Taxonomy of educational objectives: The classification of educational goals. Handbook 1: Cognitive domain. New York, NY: David McKay.
Bymer, M., Jacobs, A., Layne, C., Pynoos, R. Ruzedk, J., \& Steinberg, A. (2006). Psychological first aid: Field operations guide ( $2^{\text {nd }}$ ed.). Washington, DC: Department of Veterans Affairs.

Carbo, M., Dunn, R., \& Dunn, K. (1986). Teaching students to read through individual reading styles. New York, NY: Allyn \& Bacon.

Church, D. (2009). The treatment of combat trauma in veterans using EFT (emotional freedom techniques): A pilot protocol. Traumatology, 16, 55-65. doi:10.1177/1534765609347549

Cordesman, A. H., \& Burke, A. A. (2012). The U.S. cost of the Afghan War: FY2002FY2013: Cost in military operating expenditures and aid and prospects for "transition." Retrieved from CSIS: Center for Strategic \& International Studies website: http://csis.org/publication/uscost-afghan-war-fy2002-fy 2013

Cozza, S. J. (2015). Meeting the intervention needs of military children and families. Journal of the American Academy of Child and Adolescent Psychiatry, 54(4), 247-248. doi: $10.1016 /$ j.jaacap.2015.01.012

Flemming, N. (2001). VARK a guide to learning styles. Retrieved from http://www.vark-

learn.com/english/page.asp?p=categories 
Gagne, R. (1962). Military training and principles of learning. American Psychologist, 17, 263-267. doi: $10.1037 / \mathrm{h} 0048613$

Hallowell, E. M., \& Ratey, J. J. (1994). Driven to distraction. New York, NY: Pantheon Books.

Huber, M. T., \& Hutchings, P. (2005). The advancement of learning: Building the teaching commons. San Francisco, CA: Jossey-Bass.

Huber, M. T., \& Hutchings, P. (2013). Connected science: Strategies for integrative learning in college. T. A. Ferrett, D. R. Geelan, W. M. Schlegel, \& J. L Stewart (Eds). Bloomington, IN: Indiana University Press.

Hutchings, P., Huber, M. T., \& Ciccone, A. (2011). The scholarship of teaching and learning reconsidered: Institutional integration and impact. Hoboken, $\mathrm{NJ}$ : John Wiley \& Sons, Inc.

Ingala, A., Softas-Nall, L., \& Peters, A. (2013). The role of social support in veteran's college adjustment. International Journal of Humanities and Social Science, 3(11), 14-21. Retrieved from http://www.ijhssnet.com/

Johnson, S. (1998). Who stole my cheese? New York, NY: Penguin Group.

Marzano, R. J. (2003). What works in schools: Translating research into action. Alexandria, VA: ASCD.

Marzano, R. J., \& Heflebower, T. (2011). Teaching \& assessing $21^{\text {st }}$ century skills. Bloomington, IN: Marzano Research Laboratory.
McDonough, V. T. (2013, April 12). Helping veterans succeed in college. Retrieved April 7, 2015 from http://www.brainlinemilitary.org

Resources for returning war veterans. (n.d.). Retrieved from James Madison University, Resources \& Self-Help website:

https://www.jmu.edu/counselingctr/reso urces/for-veterans.shtml

Rose, M. (2010, March 19). Soldiers in the classroom. Retrieved from Inside Higher

Ed, Views website: https://www.insidehighered.com/views/ 2010/03/19/rose

Schafer, S. M. (2014, April 4). Many returning vets bound for college. Washington Times. Retrieved from http://www.washingtontimes.com/news/ 2014/apr/4/many-returning-militaryvets-bound-for-college/?page=all s

Sherman, N. (2010). The untold war: Inside the hearts, minds, and souls of soldiers. New York, NY. W.W. Norton \& Company.

Veterans returning to college face unique challenges. (n.d.). Retrieved from Military.com, Veteran Jobs, Career Advice, Military Transition Archive website:

http://www.military.com/veteranjobs/career-advice/militarytransition/veterans-in-college-facechallenges.html 
Appendix

Data Gathering Tools

\section{Learning Styles Questionnaire}

Select the level at which you agree or disagree with each of the following statements about how you prefer to learn.

1. Given a choice I tend to draw $\begin{array}{cc}\text { Not like me } & \text { Not like } \\ \text { at all } & \text { me }\end{array}$ Like me

Very much me

diagrams or construct a model to

1

2

3

4 help me learn something.

2. In class, I usually remember what I see best.

3. Explanations I hear stick with me better than things I read.

4. Often I cannot really explain how I've learned something.

5. I take a lot of notes in class, but afterwards, I do not always carefully review or look them over to prepare for a test.

6. Charts or graphs help me understand information better than explanations.

7. In learning situations, I prefer lectures or spoken presentations.

8. When it comes to how a concept is presented, I do not really have a preference for one style or another.

9. To show my mastery of a concept, I would prefer to build an example using the principles I have learned than to discuss them.

10. When I recall things I have learned, I often see "pictures in my mind" rather than "hearing voices."

11. I rarely feel the need to take notes as I listen to a class lecture or discussion.

12. When it comes to remembering concepts or ideas, things often just seem to "pop into my mind" and then I know them.

13. If I want to remember something, I really have to "do it".

14. Pictures and photographs help me to understand or remember ideas or concepts.

15. When I think of people, I often hear their voices in my mind.

16. Pictures and verbal information work about equally well to help me remember things.

\begin{tabular}{|c|c|c|c|}
\hline 1 & 2 & 3 & 4 \\
\hline 1 & 2 & 3 & 4 \\
\hline 1 & 2 & 3 & 4 \\
\hline 1 & 2 & 3 & 4 \\
\hline 1 & 2 & 3 & 4 \\
\hline 1 & 2 & 3 & 4 \\
\hline 1 & 2 & 3 & 4 \\
\hline 1 & 2 & 3 & 4 \\
\hline 1 & 2 & 3 & 4 \\
\hline 1 & 2 & 3 & 4 \\
\hline 1 & 2 & 3 & 4 \\
\hline 1 & 2 & 3 & 4 \\
\hline 1 & 2 & 3 & 4 \\
\hline 1 & 2 & 3 & 4 \\
\hline 1 & 2 & 3 & 4 \\
\hline
\end{tabular}


Dr. Michel Sportsman has been a full time member of the Park University School for Education faculty for over five years. He is particularly interested in effective instruction, teacher preparation, and student success. He is an active duty military veteran of the Viet Nam era.

Lisa C. Thomas is a military spouse with experience in teaching $\mathrm{K}-5$ and in higher education settings. She currently resides in Texas: email drlisa2010@yahoo.com. 